\title{
Relação e sistema: duas palavras-chave na trajetória da teoria tonal
}

\author{
Relationship and system: two keywords in the path of tonal theory
}

Sérgio Paulo Ribeiro de Freitas

Universidade do Estado de Santa Catarina

\begin{abstract}
Resumo: Percebendo relação e sistema como idealizações que se destacam em nossas práticas teóricas e analíticas, o artigo comenta algo acerca de significados e entendimentos que tais termos acumulam e dispersam na trajetória centro-europeia da teoria tonal. $\mathrm{O}$ texto passa por referências e temáticas que tocam outras áreas (tais como história, filosofia, sociologia, ciência etc.) visando, com isso, reiterar esforços de contraposição às interpretações que lidam com as noções da teoria tonal como grandezas desistorizadas e autônomas. Em conclusão observa-se que, com força prescritiva e valorativa, relação e sistema são noções polifônicas que, em movimento, tecem densos contrapontos com outras vozes.
\end{abstract}

Palavras-chave: Teoria e análise musical; Vocabulário da harmonia tonal; Metáforas como mediação pedagógica

\begin{abstract}
Based on the perception about relationship and system as idealizations that stand out in our theoretical and analytical practices, the aim of the current article is to address the meanings and understandings that these terms accumulate and outspread in the Central-European path of tonal theory. The article approaches references and topics previously addressed in other fields such as History, Philosophy, Sociology, Science, among others, in order to highlight efforts opposed to interpretations that categorize the concepts of tonal theory as ahistorical and autonomous magnitudes. It was possible concluding that, due to prescriptive and evaluative forces, relationship and system are polyphonic concepts that, once in movement, weave dense counterpoints with other voices.
\end{abstract}

Keywords: Musical theory and analysis; Vocabulary of tonal harmony; Metaphors as pedagogical mediation 
Há uma passagem escrita por Thomas Mann em seu romance "Doutor Fausto: a vida do compositor alemão Adrian Leverkühn narrada por um amigo" em que, no início de sua sombria jornada, o protagonista mostra-se iluminado pelas deduções que vai tirando a partir de experimentos em um pequeno teclado:

Um acorde como este - opinou - não tem em si nenhuma tonalidade. [...] Da relação depende tudo. E se quiseres dar um nome mais adequado a ela, chama-a "ambiguidade"! [...]. Sabes o que acho? - perguntou. -Que a Música é a ambiguidade organizada como sistema. Pega este ou aquele tom. Podes entendê-lo assim, ou também assado, [...] e, se fores hábil, conseguirás aproveitar à vontade o duplo sentido (Mann 2000, p. 70-71).

Essa passagem é convidativa para pensarmos sobre noções interligadas que, ora mais ora menos, se deixam notar em argumentos prescritivos e valorativos que ressoam nas práticas teóricas da harmonia tonal. A noção proeminente aqui diz respeito à dubiedade ou múltiplo significado dos acordes - "chama-a ambiguidade". Nos estudos do legado teórico austro-germânico, tal temática é conhecida como Mehrdeutigkeit, termo técnico musical que foi assim esclarecido por Jacob Gottfried Weber no Versuch einer geordneten Theorie der Tonsetzkunst zum Selbstunterricht que publicou a partir de 1817:

Múltiplo Significado (Mehrdeutigkeit) é como chamamos a possibilidade de explicar uma coisa [entidade] em mais de uma maneira, ou a qualidade de uma coisa, de modo que [tal coisa ou qualidade] possa ser considerada por vezes como isto e, por vezes, como aquilo. Cada tecla [nota] possui Múltiplos Significados, pode significar por vezes Fá\#, por vezes Solb; por vezes Ré\#, por vezes $\mathrm{Mi}$ ); por vezes Réx, por vezes Fáb; e, cada nota, pode aparecer e ser empregada por vezes com um ou, por vezes, com outro caráter e relacionamento (Weber apud Saslaw 1992, p. 94). ${ }^{1}$

Nas deduções de Leverkühn, esta noção de ambiguidade tonal - que não será comentada na presente oportunidade - é uma espécie de eixo que se articula com outras duas: uma delas, insinuando interdependências e comparações, se destaca no mote: "da relação depende tudo". E a outra, implicando conjunto logicamente ordenado que permite operações dedutivas, é a noção de sistema: "a música é a ambiguidade organizada como sistema”. Considerando que, por si só, esses dois termos - relação e sistema - não chegam a encerrar as implicações e

\footnotetext{
1 Sobre o Múltiplo Significado, cf. Bernstein (2006, p. 779-788), Damschroder (2008, p. 155-161), Grave e Grave (1988, p. 34-40), Hyer (2006, p. 734-735), Moreno (2004, p. 128-167), Saslaw (1992), Saslaw e Walsh (1996) e Wason (1995, p. 14-15).
} 
MUSICA THEORICA Revista da Associação Brasileira de Teoria e Análise Musical 2018, v. 3, n. 2, p. 203-226 - Journal of the Brazilian Society for Music Theory and Analysis @ TeMA 2018 - ISSN 2525-5541

variantes de sentido que enunciam, vale revisar memórias e desmemórias que podem nos ajudar a refletir sobre uma pergunta mais ou menos assim: o que se quer dizer quando, lidando com a teoria da harmonia tonal, ouvimos ou repetimos tais palavras-chave?

\section{Da relação depende tudo}

Entre o objetivismo e o relativismo o mote "da relação depende tudo" é uma clara opção pelo segundo. É, em âmbito estético, uma espécie de oposição aos que afirmam que a beleza é um traço objetivo contido nas coisas belas. $\mathrm{Ou}$ seja, o elogio à relação confronta defesas como a do estoico Marco Aurélio (121180) que em suas recordações sustentou que: "tudo o que é belo, não importa o modo como o seja, é belo em si mesmo, está determinado em si mesmo" (Aurélio apud Oliveira 2004, p. 154). O mote relativista, então, nega este "o belo" defendido pelos chamados objetivistas que defendem que:

Certas proporções e disposições são belas em si mesmas [...] o pitagórico Filolaus afirmava que o belo "é um princípio do ser". "O belo", escrevia Platão, "não é belo por alguma outra coisa, senão por si mesmo e para sempre" [...] Essa conviç̧ão se manteve intacta na estética cristã [...] e também durante o Renascimento, Alberti [o humanista italiano Leon Battista Alberti, 1404-1472] escreveu que se algo é belo, o é por si mesmo, quasi come di se stesso proprio (Tatarkiewicz 2002, p. 163).

Acompanhando o relato de Tatarkiewicz (2002, p. 166-167) observa-se que a maturação da moderna harmonia de acordes se dá, em linhas gerais, no mesmo cenário em que ocorrem as transformações "que preparam o caminho para a relativização e, por fim, a subjetivação da noção de beleza". Tal relativização não é propriamente uma tendência moderna. Mesmo Santo Agostinho (354-430) filósofo que fez do numerus a base de sua doutrina estética - já defendia que "a beleza não reside no número enquanto tal [...] a beleza é uma relação, é uma harmonia das partes" (Agostinho apud Tatarkiewicz 1989, p. 54). Tempos depois esse entendimento relacional foi renovado, ainda sem grande aceitação, pelo contestador Giordano Bruno (1548-1600) que, por seu turno, dizia: "nada é absolutamente belo, se uma coisa e bela, o é em relação a algo" (Tatarkiewicz 2002, p. 167). E já implicando na formação do ideário que alcançará Jean-Phillippe Rameau (1683-1764), ${ }^{2}$ a noção se atualiza e se torna mais espessa numa carta que

${ }^{2}$ Cf. Christensen (1993, p. 11-15). 
o filósofo René Descartes (1596-1650) escreveu ao teórico musical Marin Mersenne (1588-1648) em 1630: “a beleza não significa outra coisa que a relação que nosso juízo mantém com um objeto" (Tatarkiewicz 1991, p. 480-481). Tatarkiewicz lista outros notáveis do século XVII que se posicionaram contra a defesa do belo como algo em si mesmo determinado: para o filósofo francês Blaise Pascal (1623-1662) é "o costume que determina o que é considerado belo". Baruch de Spinoza (1632-1677), outro dos grandes da filosofia moderna, considerava que "se fôssemos criados de um modo diferente, pensaríamos que são belas as coisas feias e vice-versa". Para o filósofo inglês Thomas Hobbes (1588-1679), aquilo que consideramos belo "depende da educação, da experiência, da memória e da imaginação que recebemos". Aos finais do século de Descartes, para o naturalista francês Claude Perrault (1613-1688), “a beleza é basicamente uma questão de associações. [...] Durante dois mil anos se pensou que certas proporções eram objetivas e absolutamente belas, porém nos agradam simplesmente porque estamos acostumados a elas" (Perrault apud Tatarkiewicz 2002, p. 167).

A gradual e polêmica transição da concepção objetiva da beleza para outras, mais subjetivas e circunstanciais, segue adiante, perpassa o XVIII, e com o filósofo alemão Immanuel Kant (1724-1804), destaca Tatarkiewicz, se dá “o grande acontecimento da estética" de um século que pôde ouvir Rameau, Rousseau, Bach e Mozart: para Kant, “todos os juízos de beleza são juízos individuais. [...] se algo é belo ou não [...] não se deduz de nenhum tipo de proposição geral", sendo assim, desacredita-se o rigoroso silogismo objetivista “a qualidade $\mathrm{Q}$ determina se um objeto é belo ou não; o objeto $\mathrm{O}$ possui a qualidade Q; logo o objeto $\mathrm{O}$ é belo" -, pois não existe verdade em premissas do tipo "A qualidade $Q$ determina se um objeto é belo". Com isso, as proposições concernentes ao belo passam a ser percebidas como "generalizações indutivas que se baseiam em enunciados individuais" (Tatarkiewicz 2002, p. 176). Ressalvase, entretanto, que como se sabe, o criticismo kantiano não defende o desvario ou um relativismo a perder de vista, senão uma postura subjetivista judiciosa: um “juízo reflexionante" (Barros e Gerling 2009, p. 91) que sustenta um ideal de beleza relativo ao sujeito e à interioridade, mas dotado também de elementos objetivos e universais. Um juízo crítico que nos alcançará, ainda que de maneira não rigorosa, com a teoria contemporânea da harmonia que recorre a operadores relativos (tais como: tônica, subdominante, dominante, repouso, movimento, 
MUSICA THEORICA Revista da Associação Brasileira de Teoria e Análise Musical 2018, v. 3, n. 2, p. 203-226 - Journal of the Brazilian Society for Music Theory and Analysis@ TeMA 2018 - ISSN 2525-5541

preparação, resolução etc.) que guardam uma margem de subjetividade sem, todavia, cair num licencioso "tudo é relativo".

Nessa longa trajetória, aqui sucintamente relembrada, no anseio de apreender também a verdade interna ou espiritual acerca das escolhas de acordes - e não só a verdade visível, objetiva e material dos intervalos que tocamos e que, por muito tempo, foi a demanda técnica prioritária -, a teoria da harmonia viveu o seu próprio processo de remodelação, relativização e subjetivação. Desejando expandir e controlar a potencialidade abstrata e a pluralidade das associações entre notas, intervalos e acordes, a longeva teoria das proporções sonoras teve que ceder espaço e aprender a conviver com teses mais recentes, modernas e contemporâneas, prioritariamente voltadas para a descrição das relações entre tais notas, intervalos e acordes. Prioridade que Goethe parece destacar quando, atento ao aspecto da associação ou colateralidade entre os sons musicais, mostrando-se convicto da insuficiência das razões do monocórdio, em 1829 escreve: "Muito do que é belo está isolado no mundo, porém, o espírito tem de descobrir as ligações e, com isso, produzir obras de arte" (Goethe 2005, p. 259).

Sendo assim, buscando ligações, no âmbito do universo harmônico tonal aprendemos que a beleza e o sentido estão no entre acordes e não propriamente nos acordes. Tal elogio às relações se deixa notar nas bases daquilo que, entre finais do século XVIII e inícios do XIX, aprendemos com a Stufentheorie, a "teoria do movimento e sucessão dos graus" (Schenker 1990, p. 309). ${ }^{\text {E, }}$ mais tarde, entre finais do século XIX e inícios do XX, naquilo que apreendemos com a harmonia funcional, uma concepção da nossa arte que nos fez pensar "função" como "a propriedade de um determinado acorde, cujo valor expressivo depende da relação com os demais acordes da estrutura harmônica" (Koellreutter 1980, p. 13). Pensar que "podemos usar o termo 'função' para denotar relações significativas ou repletas de sentido dentro de uma tonalidade" (Kopp 2002, p. 6). Ou então, nas palavras do próprio Riemann: "o termo função descreve [...] os vários significados que os acordes possuem, dependendo da sua posição em relação à tônica, na lógica da composição [Tonsatz]" (Riemann apud Rehding 2008, p. 188).

Procurando narrar a trajetória da tonalidade harmônica, musicólogos, estetas e historiadores destacam aspectos do influxo transdisciplinar motivado pela noção de relações. Dahlhaus (1990, p. 22) recupera que, em 1752 - naquela

\footnotetext{
${ }^{3}$ Sobre a teoria dos graus cf. Bernstein (2006, p. 778-788) e Damschroder (2008, p. 8-9).
} 
leitura particular que faz das ideias de Rameau em seu "Élements de musique...", o influente filósofo francês Jean le Rond d'Alembert chamou de "harmonia" não os acordes "isolados", mas sim a sua combinação: "É chamado acorde a mistura de vários sons ouvidos de uma só vez; e a harmonia é propriamente uma série de acordes que em se sucedendo agradam o órgão [ouvido]" (D'Alembert apud Carvalho 2018, p. 59). ${ }^{4}$

D’Alembert relê Rameau, mas também relê o filósofo Denis Diderot. No ensaio "Pensamentos sobre a interpretação da natureza", Diderot deixa formulações que ainda podem ser parafraseadas pelos defensores da unidade funcional da harmonia tonal: "a independência de um só fato [digamos: nota, intervalo, acorde] é incompatível com a ideia do todo, e sem a ideia do todo não há filosofia [não há harmonia]"; ou um pouco mais, na descoberta das relações entre e objetos e fenômenos naturais e o processo do pensamento, "é preciso prender-se unicamente a seu objeto [digamos, um acorde] e atormentá-lo, por assim dizer, até que se tenha de tal modo encadeado os fenômenos que um deles sendo dado [p.ex., um IV grau], todos os outros igualmente o sejam" (Diderot apud Dobránszky 1992, p. 143). Fubini (1994, p. 211-213; 2002, p. 143-150) salienta que, nas bases dessa estética das relações está justamente o primeiro trabalho de Diderot inteiramente dedicado à música: o Príncipes généraux d'acoustique que integra a Mémories sur différents sujets de mathématique. Nesse trabalho, de 1748, Diderot esboça sua famosa "teoria das relações" referindo-se especificamente ao mundo dos sons: “O prazer da música consiste na percepção da relação dos sons". Três anos depois, no verbete Bello da Encyclopédie, a noção reaparece generalizada: “Porém esta origem não é exclusiva do prazer da música. O prazer em geral consiste na percepção das relações. Esse princípio se verifica na poesia, na pintura, na arquitetura, na moral, em todas as artes e em todas as ciências" (Diderot apud Fubini 2002, p. 143). Por colocações assim dá-se a perceber que,

O conceito de relações permeia [...] todo o pensamento de Diderot: elas constituem o fundamento de todo conhecimento como aquisição, como andamento do espírito humano. Estabelecer relações entre coisas significa seguir uma concepção do saber que se constrói sobre interdependência/interpenetração entre o objeto e o sujeito: o conhecimento é um processo contínuo, uma interpretação (Dobránszky 1992, p. 143).

\footnotetext{
${ }^{4}$ Sobre os encontros e desencontros entre Rameau e D'Alembert, cf. Bernard (1980), Christensen (1993, p. 255-290) e Fubini (2002, p. 76-78).
} 
MUSICA THEORICA Revista da Associação Brasileira de Teoria e Análise Musical 2018, v. 3, n. 2, p. 203-226 - Journal of the Brazilian Society for Music Theory and Analysis@ TeMA 2018 - ISSN 2525-5541

Assim, em duro golpe contra os fundamentos objetivistas, naturalistas e materialistas da "grande teoria da beleza", fundamentos ainda determinantes para as teses de Rameau, conclui Fubini: para Diderot "a faculdade da percepção das relações é uma lei psicológica", a lei que tende a simplificar o mais possível, que procura a relação mais simples e que, embora eterna e universal, se modifica "dependendo de quem capta essas percepções". Evidencia-se então que, também para Diderot, o belo não é algo que exista em si, senão um valor que varia de um lugar para outro, de uma cultura para outra e de um tempo histórico para outro.

Rameau, estética e filosoficamente "desatualizado", como diz Fubini (2002, p. 57), ainda defende o valor do acorde em si, pois, na busca de comprovação científica para suas teses, insiste na natureza como o modelo a ser imitado. Para Rameau, é desse modelo - especialmente firmado na noção de corps sonore, a proporção lógica e simples que gera o acorde da natureza, demonstrável física e matematicamente - que decorem os mecanismos da arte:

O corpo sonoro, que eu chamo, com razão de som fundamental, esse princípio gerador e ordenador de toda a música, essa causa imediata de todos os seus efeitos, o corpo sonoro, digo, não ressoa sem produzir ao mesmo tempo todas as contínuas proporções das quais nascem a harmonia, a melodia, os modos, os gêneros, e até mesmo as menores regras necessárias para a prática (Rameau apud Videira 2006, p. 36).

Em oposição ao anacrônico valor ramista da materialidade natural do acorde, D'Alembert e Diderot argumentam que, conquanto o acorde seja concernente ao corps sonore, tanto a percepção quanto a combinação de acordes decorrem, nitidamente, das ações dos seres humanos: expressam a volição do sujeito e não a natureza. E, ainda que Rameau recorra à hierarquia das progressões de quinta e de terça como forças da natureza que explicam o que se passa entre os acordes, esse calcanhar-de-aquiles da sua teoria não passou despercebido aos olhos desses dois enciclopedistas que, com tal atenção crítica, muito contribuíram para a propagação e aperfeiçoamento da nossa disciplina: a natureza pode até produzir acordes demonstráveis física e matematicamente, mas a natureza não exerce a vontade de escolher e interpretar relações entre os sons musicais.

Dahlhaus (1999, p. 145) notou esse argumento destacando que a vontade humana de estabelecer e apreciar relações artísticas (ou artificiais) se opõe às defesas naturalistas e cientificistas da harmonia. Argumento que Jean-Jacques 
Rousseau (1712-1778), o arquirrival de Rameau, também não deixou de reclamar ao comentar os corpos sonoros num texto que - prenunciando as deduções de Adrian - já esboça fundamentos para uma doutrina dos múltiplos significados.

Um som não tem, em si mesmo, nenhum caráter absoluto que permita reconhecê-lo: é grave ou agudo, forte ou suave, em relação a outro; em si mesmo não é nada disso. No sistema harmônico, um som qualquer também nada é em sua natureza; não é tônico nem dominante, nem harmônico, nem fundamental, porque todas essas propriedades são apenas relações e porque o sistema inteiro podendo variar do grave ao agudo, cada som muda de ordem e de lugar no sistema, acompanhando a mudança de grau do sistema (Rousseau 2008, p. 162-163).

Noções assim - de interpretação, relativização e subjetivação repercutiram na contemporaneidade e, com elas, passamos a acreditar que é a relação que significa. O que conta é aquilo que aproxima e afasta os acordes. E esta relação é uma ideia, algo impalpável, intocável, imaterial: não é uma coisa, e sim uma função. Uma instância que não está propriamente nos objetos da natureza, no fenômeno físico-sonoro como insistia Rameau, senão na subjetividade de um "homem histórico que escuta e compreende segundo suas disposições momentâneas, sua cultura, sua educação etc." (Fubini 2002, p. 146).

No que será a nova perspectiva estética e teórica para a harmonia, por si só, o objeto acorde tem mesmo uma importância relativa. Assim, quando no "Doutor Fausto" o neófito Leverkühn toma consciência de que "um acorde como este não tem em si nenhuma tonalidade. [...] Da relação depende tudo" (Mann 2000, p. 70), é possível perceber ressonâncias que alcançam uma das máximas funcionalistas reditas pelo experiente Schoenberg: "uma tríade sozinha é totalmente indefinida quanto ao seu significado harmônico; pode ser a tônica de uma tonalidade ou um dos graus de muitas outras" (Schoenberg 2004, p. 17).

Observa-se que, no "Doutor Fausto", esse tomar consciência é parte de uma espécie de encadeamento dedutivo que, de modo instigante, coliga as descobertas de Adrian a uma espécie de determinismo histórico que orienta a trajetória ocidental da técnica musical. Do deslumbre pitagórico platônico de Adrian pela matemática - pela "Mathesis, como lógica aplicada, que todavia, se conserva nos puros e altaneiros domínios do abstrato"- surge o prazer em "observar relações de ordem". Desse encanto pela ordem - "a ordem é o essencial" (Mann 2000, p. 68-69) - surge outra descoberta: Adrian encontra a arte dos sons e, sozinho, deduz o nexo tonal que existe entre os sons em acordes. Tal 
MUSICA THEORICA Revista da Associação Brasileira de Teoria e Análise Musical 2018, v. 3, n. 2, p. 203-226 - Journal of the Brazilian Society for Music Theory and Analysis@ TeMA 2018 - ISSN 2525-5541

deduzir sozinho é um requisito essencial para a noção cartesiana de sujeito pensante (cogito), conforme se lê numa célebre passagem do Discours de la Méthode (1637) em que Descartes (como Adrian e outros decifradores da harmonia) afirma: "eu não podia escolher ninguém cujas opiniões me parecessem dever ser preferidas às dos outros, e encontrava-me como que obrigado a procurar conduzir-me a mim próprio" (Descartes apud Santos 1988, p. 49). Essa atitude cartesiana que de tudo duvida - de omnibus dubitandum - se encontra também em Rameau (numa sentença impetuosa que parece proferida pelo próprio Leverkühn):

Conduzido desde minha mais terna juventude por um instinto matemático no estudo de uma Arte para a qual me encontrava destinado, e que tem ocupado exclusivamente toda minha vida, quis conhecer o verdadeiro princípio, como o único capaz de guiar-me com certeza, sem consideração pelos hábitos nem pelas regras recebidas (Rameau 1750, p. 110). ${ }^{5}$

Então, numa primeira e curta etapa de sua vida, Adrian parece refazer os passos de vários personagens que dedicaram (e ainda dedicam) suas vidas a essa arte e ofício - passos de um Descartes e de um Mersenne, de um Rameau e de um Rousseau, de um Forkel e de um Riemann, e também, mas não somente, os passos de Schoenberg - deduzindo que o universal está na ordem, a ordem está na matemática e a matemática está na música. Tais decorrências revigoram as regras cartesianas para a direção do espírito, o abstrato essencial, a ciência geral capaz de se fazer deduzir por si própria. ${ }^{6}$ Em síntese, temos um jogo de ilações:

\footnotetext{
5 «Conduit dès ma plus tendre jeunesse, par un instinct mathématique dans l'étude d'un Art pour lequel je me trouvais destiné, et qui m'a toute ma vie uniquement occupé, j'en ai voulu connaitre le vrai principe, comme seul capable de me guider avec certitude, sans égard pour les habitudes ni les règles reçues» (Rameau 1750, p. 110).

${ }^{6}$ Leverkühn parece conhecer as Regulae ad directionem ingenii, obra iniciada por Descartes logo após o Compendium musicae, mas publicada postumamente em 1684. Conforme Huisman (2002, p. 478), as "Regras para a direção do espírito" contêm uma exposição geral do método cartesiano e reafirmam a sua universalidade, uma espécie de irrestrita generalização baseada na ideia de uma ordem única, análoga a ordem matemática. Huisman resume as regras: "Seja qual for o problema encontrado, será preciso decompor as proposições obscuras nas proposições simples de que são compostas. Por isso, examinaremos o enunciado do problema para 'enumerar' seus diferentes termos, a fim de separar os conhecidos dos desconhecidos. Em seguida, poremos esses termos em ordem, tentando descobrir a razão de sua série. Por fim, serão dispostos de tal modo que, conhecendo o primeiro termo e razão da série, poderemos reconstruir a série inteira; é o caso da série de uma progressão aritmética ou geométrica em que faltem certos termos: eles podem ser facilmente descobertos graças à razão da série, a partir dos termos conhecidos".
} 
na Europa, entre a revolução científica, a época das Luzes e o pré-romantismo, a tonalidade harmônica é como "uma criança que cresce para se tornar um gigante colossal", 7 ao passo que, no romance, Adrian cresce descobrindo como a música tonal opera para logo intuir um próximo e inevitável passo em direção ao pós tonal. Suas descobertas e conflitos, de maneira teleológica, correspondem ao próprio percurso da tonalidade. Como nesse momento da trama Adrian vive a adolescência - "tinha ele quatorze anos" (Mann 2000, p. 69) - e, na medida do possível, ainda é feliz (i.e., ingênuo), suas descobertas correspondem aos anos de juventude da harmonia. Adrian, então, redescobre aquelas relações que foram descobertas nos séculos XVII e XVIII: “os acordes, a rosa-dos-ventos das tonalidades, o ciclo das quintas", as dominantes, "as modulações enarmônicas entre tonalidades remotas", a "sexta napolitana", as "afinidades de terceira" etc. (Mann 2000, p. 69-70).

Reitera-se, então, o entendimento da harmonia tonal como um conjunto logicamente organizado de elementos dotados de capacidade relacional plurissignificante. Entendimento que ocorreu a Rameau que, no Prefácio do Traité de 1722, escreveu a conhecida e esperançosa passagem: “a música é uma ciência que deve ter regras certas; estas regras têm que derivar de um princípio evidente e este princípio não se revela a nós sem o auxílio das matemáticas" (Rameau 1971, p. xxxv). Que ocorreu ao teórico alemão Johann Nikolaus Forkel que, em 1788, defendeu "a harmonia como uma lógica da música" (Dahlhaus 1999, p. 104). E que ocorreu a Riemann que, destacando a noção harmônica de "representação sonora" (Tonvorstellung), defendeu que a escuta musical é uma atividade altamente desenvolvida de "funções lógicas do espírito humano" (Mastropasqua 2011, p. 130).

Para finalizar o comentário acerca do mote "da relação depende tudo", com a contribuição de Cassirer (1997, p. 42), vale sublinhar que: para o sujeito moderno "não basta que os fatos estejam 'ao lado' uns dos outros, é preciso que eles se encaixem uns 'nos' outros, que a simples coexistência se revele como dependência, e a forma de agregado converta-se em forma de sistema". Ou como conclui Leverkhün através da observação, da confrontação e da experimentação:

\footnotetext{
${ }_{7}$ Outra analogia, próxima ao mundo de Rameau, que aparece em um sonho do iluminista Diderot lembrado por Gaines (2007, p. 160): “O sonhador se vê transportado para um enorme prédio suspenso no espaço, habitado por homens frágeis, velhos e deformados. Então, uma pequena criança saudável entra, cresce para se tornar um gigante colossal e destrói o prédio".
} 
MUSICA THEORICA Revista da Associação Brasileira de Teoria e Análise Musical 2018, v. 3, n. 2, p. 203-226 - Journal of the Brazilian Society for Music Theory and Analysis@ TeMA 2018 - ISSN 2525-5541

é preciso estabelecer uma lógica dos fatos, algo capaz de reduzir a diversidade dos fenômenos a um princípio inteligível, e que tal princípio nos permita controlar e apreciar a diversidade através de uma ideia de sistema.

\section{A música é a ambiguidade organizada como sistema}

Uma definição de sistema é: "conjunto de elementos relacionados entre si funcionalmente, de modo que cada elemento do sistema é função de algum outro elemento, não havendo nenhum elemento isolado" (Mora 2004, p. 2703). Com essa definição introdutória advinda do campo da lógica filosófica, é valioso notar que, de maneira semelhante ao que se passa com a noção de relação, também a trajetória moderna da noção de sistema - conforme narram Abbagnano (1982, p. 875-877), Dobránszky (1992, p. 129-143), Mora (2004, p. 2703-2708) e Scott (2010, p. 184-188) - é algo coincidente com o processo de consolidação da teoria tonal.

No campo da sociologia, ponderando que sistema implica relações de interdependência entre as partes e o todo, e que a compreensão dessa interdependência favorece análises abrangentes, capazes de revelar articulações extensas, sem uma necessária descrição dos detalhes de cada parte ou elemento individualmente, Scott observa que

A ideia geral de sistema tem origem nas ciências naturais, que procurou estabelecer seus conceitos em duas principais direções: os sistemas mecânicos estudados em física e os orgânicos, em biologia. Analogias com esses dois conceitos forneceram os principais modelos sociológicos de sistemas [...]. Ainda que algumas visões contemporâneas reflitam uma ou outra dessas analogias, a maioria das abordagens combina elementos de ambas (Scott 2010, p. 184-185).

Algo dessa observação sociológica parece se aplicar ao campo musicológico, pois também na interpretação da tonalidade como um sistema se observam essas duas direções. Animados e animando a ciência que investiga as leis do universo, a teoria tonal conta com analogias mecânicas que, baseadas na física do século XVIII, nos permitem falar em distâncias, movimentos, forças de atração e repulsão e, de modo especial, generalizar paralelismos entre a teoria gravitacional e a harmônica: "[Tônica] Nota principal e o centro de gravidade da tonalidade que tem o seu nome" (Candé 1989, p. 222); “O pensamento tonal clássico fundamenta-se num universo definido pela gravitação e pela atração" 
(Boulez 1995, p. 272); “A coesão tonal não é senão a força da gravidade em sua forma mais extremamente sutilizada" (Hindemith 1962, p. 113).

A tonalidade pode ser definida como um sistema de relações de acordes baseado na atração exercida por um centro tonal. Esta tônica cria o centro de gravitação para os outros acordes. Não é uma mera metáfora explicar a tonalidade em termos de gravitação. Tanto a tonalidade quanto a gravitação foram descobertas do período barroco feitas exatamente ao mesmo tempo (Bukofzer 1947, p. 12)

Examinando desdobramentos e implicações envolvidas em tais paralelismos, Christensen (1993, p. 185-190) observa que o próprio Rameau evoca esse newtonianismo, muito popular à época, para ilustrar o fenômeno da atração tonal. Christensen cita a descrição das relações entre tônica, subdominante e dominante - que entre si interagem com a mesma "certeza e necessidade com que a força de gravidade age sobre uma pedra" (Abbagnano 1982, p. 230) - que Rameau faz em seu Génération harmonique de 1737.

[A tônica] deve ser vista como o centro do tom, é dela que se originam todos os nossos desejos. A tônica é efetivamente o termo do meio de uma proporção em que os extremos estão ligados de tal modo que não podem se desprender dele por um único momento. A progressão passa por um destes extremos, mas tem que voltar atrás imediatamente. [...] A mútua assistência prestada entre a dominante e a subdominante as conecta ao som principal de tal maneira que elas não podem se afastar dele. A sonoridade harmônica de uma, [...] obriga a outra a se submeter à primeira, e consequentemente retornar ao som principal (RAMEAU apud Christensen 1993, p. 189).

Rameau pôde, então, ser comparado a Isaac Newton (1643-1727): se "Newton desenvolve a teoria da gravitação como explicação dos corpos celestes a partir de um princípio único" (Schwanitz 2007, p. 106), Rameau, por sua vez, desenvolve uma teoria que explica a harmonia a partir do princípio único comum aos corpos sonoros:

Inspirado pelos elementos da física newtoniana que tinham grande circulação na França durante os anos de 1730, Rameau reconceituou o acorde de tônica como um tipo de corpo gravitacional rodeado de dominantes por cima e por baixo [a dominante e a subdominante]. Cada uma dessas dominantes é atraída para a tônica ao mesmo tempo em que ajuda a constituir o modo (Christensen 2001, p. 796). ${ }^{8}$

\footnotetext{
8 Jean-Francois Marmontel inicia sua "ode à Rameau" chamando-o de "Newton des Sons, astre de l'Harmonie" (cf. Christensen 1993, p. 8). Em 1760, o astrônomo Jean-Paul Grandjean de Fouchy
} 
MUSICA THEORICA Revista da Associação Brasileira de Teoria e Análise Musical 2018, v. 3, n. 2, p. 203-226 - Journal of the Brazilian Society for Music Theory and Analysis@ TeMA 2018 - ISSN 2525-5541

Por seu turno, as analogias com a ciência que estuda a vida e os organismos vivos também são conhecidas no âmbito artístico. E, em música, ganham destaque nos paralelismos entre sistemas biológicos e entendimentos que nos ensinam encontrar conexões que realçam a função de cada "órgão", elemento ou parte, na consecução de uma unidade orgânica.

O organicismo reflete a ideia de que a obra musical é um organismo onde as partes são combinadas de forma a funcionar como um todo, utilizando o corpo como uma metáfora para a obra musical. Então o organicismo recoloca o conceito de unidade musical conforme definido através da análise musical, mas o faz por meio de noções específicas de crescimento, expansão e transformação, todas as quais relacionam-se com imagens organicistas tanto da natureza [...] quanto do corpo (Beard e Gloag 2006, p. 124, tradução de Raísa Silveira).

[O "modelo tradicional da música erudita ocidental"] uma criação característica do século XIX [...] cresceu como se proviesse de algum misterioso pool genético de origem alemã; historicismo, organicismo e nacionalismo foram todos amalgamados na ideologia musical da época; [...] quase até os dias de hoje, a contínua evolução orgânica do modelo da grande música permaneceu, para muitos músicos, um dogma inconsciente (Kerman 1987, p. 90).

O organicismo foi crucial para a história da música, pois forneceu as metáforas centrais da estética romântica. Sua influência foi tão profunda e penetrante que tem durado, com ocasionais e pouco importantes perdas de intensidade, ao longo do século XX não só em manifestações da alta cultura (Meyer, 2000, p. 292). ${ }^{9}$

Posto isso, e parafraseando Scott, podemos também inteirar que, ainda que algumas visões contemporâneas reflitam uma ou outra dessas analogias, muitas das abordagens teóricas e crítico musicais que nos cercam misturam imagens relacionadas tanto com os sistemas físicos quanto com os biológicos. $\mathrm{E}$

(1707-1788), declara: “O Senhor Rameau, tendo explicado o princípio da harmonia, dotou seu sistema da mesma plena verdade que Newton encontrou para a ótica". O historiador Inglês John Hawkins, em 1776, declara: "A obra pela qual o senhor Rameau se fez mais célebre é sua Demonstration du principe de l'harmonie..., na qual, como dizem seus compatriotas, ele demonstrou que tudo deriva de um único e evidente princípio, isto é, o baixo fundamental; por isso, eles o comparam à Newton, que com o princípio único da gravidade, conseguiu explicar todos os fenômenos físicos mais importantes; por esse motivo eles querem definir Rameau como o Newton da harmonia" (Hawkins apud Fubini 2002, p. 77).

${ }_{9}^{9}$ Sobre organicismo em teoria e análise musical, cf. Montgomery (1992), Solie (1980). 
tais misturas adensam a questão aqui em pauta: como a ideia de que a tonalidade harmônica é comparável ou é um sistema se naturalizou?

No mundo de Rameau, a noção tomou corpo crítico e filosófico em obras como o Traité des systèmes publicado em 1749 pelo pensador iluminista Estevão Bannot de Condillac (1715-1780) que, desde a introdução, propõe: sistema é a "disposição das diferentes partes de uma arte ou ciência em uma ordem em que todas as partes se sustentam mutuamente e em que as últimas se explicam pelas primeiras" (Condillac apud Mora 2004, p. 2705). Ao longo desse Traité, valorizando o método experimental e reconhecendo como verdadeiros aqueles sistemas em que o nexo entre os fatos é observável, Condillac diferencia o "espírito sistemático" do "espírito de sistema" e reflete sobre um "deslocamento do acento" que, gradualmente, alcançou nossas práticas teóricas. ${ }^{10}$ No "espírito sistemático", argumenta Condillac, a tendência metodológica que predomina é a do movimento do geral para o particular, dos princípios para os fenômenos. Com isso, nos sistemas filosóficos decorrentes, os princípios gerais se mostram como dogmas irrefutáveis, ideias primordiais e de certeza inviolável que firmadas intuitivamente alcançam a condição de axiomas universais. Nessa direção, observa Abbagnano (1982, p. 876), outros pensadores também se manifestaram. Diderot dizia: "por espírito sistemático eu designo aquele que traça planos e forma sistemas do universo, pretendendo em seguida adaptar os fenômenos a torto e a direito"; D'Alembert refere-se ao espírito sistemático como o "sonho dos filósofos"; e Hegel observou que essa tendência dos pensadores franceses seiscentistas agregou conotações de "unilateralidade e dogmatismo" ao termo sistema.

Em contrapartida - isto é, em oposição ao espírito sistemático que pensa o sistema como um a priori, um conjunto fixo, afirmado ou estabelecido sem exame, análise ou verificação -, Condillac valoriza o "espírito de sistema" do século XVIII e, conforme Christensen (1993, p. 39), cita como um "bom sistema" justamente a mencionada teoria do corps sonore de Rameau que - como também o faz o aspirante a compositor no "Doutor Fausto" - se prende aos fatos procurando deixar que os conceitos se formem em contato com esses fatos e estabeleçam vínculos com o espírito racional. ${ }^{11}$ Nesse espírito de sistema,

\footnotetext{
${ }^{10}$ Cf. Christensen (1993, p. 35-42).

${ }^{11}$ No Traité des systèmes de Condillac, como se sabe, a principal ilustração de "espírito de sistema" diz respeito ao conjunto de contribuições de Isaac Newton. Assim, compreende-se esse elogio ao
} 
MUSICA THEORICA Revista da Associação Brasileira de Teoria e Análise Musical 2018, v. 3, n. 2, p. 203-226 - Journal of the Brazilian Society for Music Theory and Analysis@ TeMA 2018 - ISSN 2525-5541

Não se busque, portanto, a ordem, a legalidade, a "razão", como uma regra "anterior" aos fenômenos, concebível e exprimível a priori: que se demonstre a razão nos próprios fenômenos como a forma de sua ligação interna e de seu encadeamento imanente. Que não se pretenda antecipar a razão sob a forma de um sistema fechado: há que deixá-la desenvolver-se a longo prazo, pelo conhecimento crescente dos fatos, e impor-se pelos progressos em sua clareza e em sua perfeição (Cassirer 1997, p. 26).

Acredita-se, por isso, que nesse espírito de sistema "a razão se define muito menos como uma possessão do que como uma forma de aquisição" (Cassirer 1997, p. 32). Digamos: a razão não é um ser, e sim um fazer. Não é um conteúdo determinado de conhecimentos, um conjunto de princípios e verdades depositadas no espírito, e sim uma energia, "o poder original e primitivo que nos leva a descobrir e a consolidar a verdade" (Cassirer 1997, p. 32). E como Rameau foi citado enquanto proponente de um sistema exemplar, ou seja, um sistema baseado em "princípios extraídos da consulta à experiência e do exame de fatos bem comprovados" (Mora 2004, p. 2705), convêm reiterar que, conservando traços ideais - como medida, precisão, ordem e proporção entre elementos diversos regidos por um princípio primordial -, o corps sonore designa "qualquer sistema vibratório que emita sons harmônicos acima de sua frequência fundamental. Desta forma, toda corda, ao vibrar, contém em si mesma o germe de toda a música" (Christensen apud Videira 2006, p. 36).

No século XVIII, conforme a exposição de Abbagnano, o termo sistema refere-se a qualquer teoria, científica ou filosófica, especialmente quando se deseja sublinhar seu caráter pouco empírico. E nesse mundo de Rameau, de fato, o termo tornou-se frequente: D'Alembert falava em "sistema de mundo" para indicar as teorias cosmológicas. Leibniz chamou de "sistema" suas teorias sobre a relação entre a alma e o corpo ou entre as diferentes substâncias. Em finais do século XVII, polemizando o "sistema ocasionalista" defendido pelo filósofo Nicolau Malebranche, o cientista Bernard Le Bovier de Fontenelle lança o ensaio Doutes sur le système physique des causas occasionnelles (Dúvidas sobre o sistema físico das causas ocasionais, 1686). Entre 1716 a 1720 a economia da França foi regida pelo inovador Système de Law idealizado pelo financista franco-escocês John Law. O botânico sueco Carlos Lineu chamou de Systhema naturae a famosa classificação hierárquica das espécies que publicou em 1735. O esteta alemão

sistema de Rameau como uma das repercussões do supracitado paralelismo entre newtonianismo e tonalismo. 
Alexander Baumgarten (1714-1762) chamava de "sistemas psicológicos" as "opiniões que parecem aptas a explicar a relação entre alma e corpo" (Abbagnano, 1982, p. 876). Em 1759, o Abbé Dufour publicou L'Ame ou le Sistème des matérialistes, soumis aux seules lumiéres de la raison (A alma ou sistema dos materialistas, sujeitos apenas à luz da razão). Em 1770, o Barão d'Holbach, possivelmente com a colaboração de Diderot, publicou um Système de la Nature ou Des Loix du Monde Physique et du Monde Moral (Sistema da natureza ou das leis do mundo físico e do mundo moral). Em 1775, o médico francês Pierre Roussel publicou um Du Système physique et moral de la femme (Do sistema físico e moral da mulher) que, contudo, foi reeditado até o século XX. E, em meio a tantos sistemas, considerando diversas acepções que o termo possui no campo musical desde a Antiguidade, Rousseau (2007, p. 370-392) dedica ao Système um dos mais extensos verbetes do Dictionnaire de musique que publica a partir de 1768.

Para reler o verbete Système de Rousseau, com o auxílio do lexicógrafo da língua portuguesa Rafael Bluteau (1638-1734), é contributivo notar que a palavra grega Systema implica coordenação, coleção, disposição ou composição criteriosa. Tal termo, informa Bluteau, foi arquitetado pelos astrônomos antigos em referência a "colocação dos grandes corpos do mundo respectivamente ao centro do Universo com suposições e hipóteses que servem de fundamento para explicar e determinar todos os fenômenos, aparências, movimentos e mudanças dos planetas e corpos celestes" (Bluteau 1713, p. 823).12 Retendo algo dessa origem e história do termo, Rousseau descreve uma derivação moderna que, em alguma medida, ainda é vigente. Assim, numa franca extensão de sentido:

Sistema [...] é a coleção de regras de harmonia extraídas de alguns princípios comuns que as agrupam, que estabelecem sua relação, dos quais derivam e pelos quais se estabelece sua razão. Até nosso século a harmonia, surgida de maneira sucessiva e como que ao acaso, não teve mais que regras esparsas, estabelecidas pelo ouvido, confirmadas pelo costume e que pareciam absolutamente arbitrárias. O senhor Rameau foi o primeiro que, mediante o sistema do baixo fundamental, estabeleceu os princípios a tais regras (Rousseau 2007, p. 378).

\footnotetext{
${ }^{12}$ Leverkühn evoca essa imagem astrológica quando, sobre a apreensibilidade de construtos musicais complexos, advoga: "Se 'ouvir' significa [...] a percepção exata de todos os meios pelos quais se obteve a suprema e mais rigorosa ordem, uma ordem análoga à do sistema solar, uma ordem e uma imutabilidade de grandeza cósmica, não, assim eles não serão ouvidos. Mas a própria ordem será, ou melhor, seria ouvida, e sua compreensão proporcionaria uma satisfação estética nunca antes sentida" (Mann 2000, p. 271-272).
} 
MUSICA THEORICA Revista da Associação Brasileira de Teoria e Análise Musical 2018, v. 3, n. 2, p. 203-226 - Journal of the Brazilian Society for Music Theory and Analysis@ TeMA 2018 - ISSN 2525-5541

Mora (2004, p. 2703-2708) destaca que filósofos do idealismo alemão (tais como Fichte, Schelling e Hegel) dispunham seus pensamentos em "sistemas" e que, ainda nessa era moderna, na "Dialética transcendental" da "Crítica da Razão Pura" que publicou em 1781, Immanuel Kant retoma a ideia de

\begin{abstract}
Sistema como um todo do conhecimento ordenado segundo princípios, e definia a arquitetônica como a arte de construir sistemas. Mas como justamente a razão humana é arquitetônica, ela pode converter em sistema o que era mero agregado de conhecimentos. Daí a definição precisa: "Por sistema entendo a unidade das formas diversas do conhecimento sob uma única ideia" [Kant], em que a ideia é o conceito dado pela razão. Por isso, segundo Kant, o conceito determina a priori não apenas o alcance do conteúdo, mas as posições recíprocas das partes, de sorte que podemos chegar a uma unidade organizada (articulatio) e não a mero agregado (coacervatio), a uma ordem que cresce desde dentro (per intus susceptionem) e não mediante sucessivas agregações (per appositionem) (Mora 2004, p. 2704).
\end{abstract}

Por essas e outras, e ainda que, após Kant, essa vivaz analogia cosmogônica possa ter sido repensada em algumas ciências e filosofias, nos habituamos a lidar com a música como um conjunto de elementos ordenados segundo princípios entre si regulados de modo a formarem uma unidade organizada e não um mero agregado. Uma arquitetônica naturalizada sobre a qual, nos anos que se seguiram, o compositor alemão Carl Friedrich Zelter (17581832) tentou alertar:

Nossa teoria tornou-se um sistema que precisa ser aprendido e ensinado. Não há dúvida de que, com isso, ocorreu em certa medida uma violentação da natureza. Trata-se, porém, de uma tessitura engenhosa de modificações que se podem observar, quase que sem nenhum espanto, já que os músicos guardam a crença de que o que não se pode edificar com esse sistema não é para ser edificado (Zelter apud Schuback 1999, p. 33-34).

Essa crença fez história e proponentes de sistemas engenhosos vieram atualizá-la. Como é o caso de Riemann que, em determinadas passagens, parece mesmo comemorá-la.

Que o meu sistema esteja destinado a sofrer no futuro outras transformações, eis o que não me parece verossímil. Bem pelo contrário, estou convencido de que, no que se refere a reportar todos acordes, até na sua cifra, às três funções Tônica, Subdominante e Dominante, obtive com os meus trabalhos uma visão definitiva a esse respeito (Riemann apud Nattiez 1984, p. 257).

E também de Schenker (1990, p. 39-175) que, enfatizando a fundamentação e a pureza dos sistemas, garantia que, como diz Rosen (2004, p. 201), “quem não 
ouvia música de acordo com seu sistema não podia dizer que ouvia música". Assim, acreditando em sistemas, consequentemente, defendemos que, em música, dependemos do formar e seguir combinações coerentes que, filosoficamente, possuam uma normalização racionalmente expressa. Com isso, entre o uso costumeiro de uma expressão fixa e a própria concepção do que seja a música, a mediação do sistema tornou-se algo obrigatória. Lembrando Adorno - "o sujeito domina a música através de um sistema racional, para sucumbir, ele próprio, ao sistema racional" (Adorno apud Carvalho 2007, p. 60) -, podemos assumir: no geral, sucumbimos aos encantos dessa duradoura e poderosa analogia.

Convêm notar então que, enquanto abstração superficial, o sistema pode se mostrar como uma noção enviesada. Ou um complicador se, de modo essencializador e pouco sensível ao assistemático ou ao antissistemático, a noção de sistema nortear descrições e apreciações sobre todo e quaisquer campos de produção, análise e crítica musical. Se a noção agrega sentidos de conjunto coerente e intelectualmente unificado por um fundamento lógico e conhecido; se sistema é algo "organizado dedutivamente constituindo um todo cujas partes se deixam extrair uma das outras" e mais, se sistema é uma ordem "de verdades ligadas entre si e com seus princípios" (Abbagnano 1982, p. 875), então, é preciso emendar que nem toda música funciona assim.

Acreditar que tudo é sistema é um meio para silenciar aquilo que, também em música, se conforma de maneira desregrada? Silenciar feitos e fazeres nãosistematizados que, por vezes, misturam fragmentos de sistemas diversos que, possivelmente, em seus âmbitos de validade, se excluíam ou se desconheciam mutuamente? Em narrativas deterministas, um sistema é algo fechado em si que segue, supera, se contrapõe ou substitui algum outro sistema (como ocorre quando estabelecemos algum tipo de finalismo entre os termos modal, tonal e pós-tonal). Mas nem todas as soluções musicais são predeterminadas por claras relações de causalidade. Por vezes a segurança de um sistema é muito baixa, um sistema chega a se isolar, mas os mais distintos elementos podem também se misturar de maneira inacabada em convivências assimétricas e instáveis e em ecletismos bastante desorganizados, ilógicos e improváveis.

Em suma, no âmbito das práticas teóricas da harmonia tonal, lidar com sistema é lidar com aquilo que se coloca entre nós e a harmonia propriamente dita. É lidar com alguma harmonologia, com algum "sistema de representação 
dos acontecimentos" (Schoenberg 2001, p. 451) que organiza e fornece definições e esclarecimentos diversos para uma boa parte das ações, conceitos e valores dessa arte e ofício. Lidar com os sistemas teóricos da harmonia é lidar com os aspectos formais desta matéria, com as segmentações de seus conteúdos programáticos, com aquilo que cabe nos capítulos de sua extensa bibliografia. É lidar com a harmonia dos pedagogos e teóricos nas suas interações com a harmonia dos músicos. É lidar com a "clareza extensa" da disciplina em contraposição com a "clareza intensa" da arte (Baumgarten apud Osborne 1983, p. 260). E novamente com Rosen (2004, p. 201) vale, por fim, recuperar a máxima do poeta alemão Friedrich Schlegel (1772-1829): “é tão fatal ter um sistema quanto não ter nenhum. Deve-se tentar combinar uma coisa com a outra". E desse modo, considerando histórias e conotações associadas ao consagrado termo, podemos tentar nos prevenir para algum nível de propaganda enganosa que possa estar escondida na naturalizadora metáfora "sistema". E então, quem sabe, melhor aproveitar as expectativas que podemos nutrir sobre as ambivalentes relações tonais.

\section{Conclusão}

Como acontece com outros vocábulos, no âmbito musical aqui considerado, ao ouvir e repetir os termos relação e sistema podemos reconhecer algo da erudição que os acompanha. Também vamos notá-los em situações coloquiais, como termos comuns que usamos sem maiores pretensões. E é possível ainda encontrá-los servindo para a legitimação de novos sentidos, sonoridades e discursos. Em suma, tomando de empréstimo a conhecida estratificação de Williams (1979, p. 124-129), nessas palavras-chave vale observar a sobreposição e a interação de camadas arcaicas, residuais e emergentes. Por seus vínculos com um passado um pouco mais distante, as noções de relation e systèmee ajudam a demarcar aspectos da fase moderna (séculos XVII e XVIII) da teoria musical. E com isso coexistem, se chocam e contribuem para o afloramento de noções outras que - como a citada noção de ambiguidade tonal - amadurecem já em sua fase contemporânea, adentrando os séculos XIX e XX, contando com os avanços da teoria tonal austro-germânica.

Enquanto pensamento geral e abstrato, as noções de relação e sistema estão correlacionadas a ideias de variedade e ordem, de vinculação e coesão hierárquica, de escolha e combinação exercida num campo de logicidades. Estão, 
com isso, correlacionadas ao valor de artisticidade como qualidade decorrente de um labor aceito como criterioso e de uma obra estimada como coerentemente unificada. Podemos apreender então que, em nossas crenças, conhecimentos e ações musicais - na fruição, criação, performance, ensino, aprendizagem, teorização e análise crítica -, tanto a inteligibilidade quanto a validade dos processos de raciocínio e imaginação são incisivamente afetadas pela presença ou ausência das relações e dos sistemas.

Assim, recuperar algo daquilo que pode estar guardado em tais noções permite notar que, com elas e entre elas se formam importâncias que, implícita ou explicitamente, também se embaralham nos pressupostos, métodos e conclusões que regem idealizações a respeito da teoria e arte da harmonia tonal. Reexaminar tais noções e embaralhamentos é tarefa que desconhece limites e que, com isso, deixa pistas de que aquilo que pensamos como e com a teoria tonal não é algo que em si mesmo se basta. Digamos: tomando parte daquilo que entendemos como música no ocidente moderno contemporâneo, nossas noções teóricas também não nos chegaram por meio de um "telefonema de outro mundo" (Nietzsche apud Ross 2009, p. 327).

No desenrolar de suas histórias que, então, tecem contrapontos com outras vozes do pensamento, essas noções-chave da teoria tonal por vezes estão em acordo com as escolhas musicais. Mas, outras vezes, tais noções e escolhas se desassociam tão notavelmente que são vistas até como coexistentes, mas independentes. Nossas noções musicais de relação e sistema vão se entendendo e se desentendendo com noções filosóficas e, com isso, os músicos se fazem filósofos, ou se identificam com algo das filosofias, e os filósofos se aproximam da música e do pensamento musical. Mas, são também muitos os esforços para que não ocorra um paralelismo simplista entre tais domínios. De modo amplo, percebe-se que, as correlações entre o "detalhe musical estrutural" e a "relação deste detalhe com a vida 'fora' da música" (Tagg 2005, p. 47) são dinâmicas e exigem vários cuidados e mediações: algumas vezes os paralelos parecem nítidos, mas em outras as supostas sintonias são demasiadamente genéricas e turvas, simpatias que não se ajustam muito bem. Em certos casos, tais correlações são tidas como confluências em uma mesma história, mas em outros são compreendidas como uma necessária diferença específica, para que não haja confusão entre o território de uns com o de outros. 
Enquanto traço da capacidade associativa, a noção de relação estabelece correspondências com o prazer da inteligência produtora e, assim sendo, também à satisfação de uma vontade, ou necessidade, vital. Opondo-se ao ilogismo e a confusão, a noção de sistema reforça intuições de unidade organizada e, logo, de verdade e pertinência. Se concordarmos que tais grandezas não são exclusivas à música e suas técnicas e materiais, essas noções mostram uma capacidade coligativa que pode favorecer vínculos entre particularidades e prescrições da nossa disciplina e determinadas visões de mundo que, sendo abrangentes, impactam a sociedade e a cultura como um todo. Essa empatia entre assuntos da música e assuntos da vida sociocultural é algo que produz efeitos sobre o juízo crítico e avaliativo acerca da nossa arte. Com isso, as noções de relação e sistema são também chaves para a compreensão de parte daquilo que, ainda que tacitamente, sustenta nossos julgamentos. Quando escolhemos abordar essas noções-chave da teoria tonal como grandezas isoladas, a disciplina tende a ser julgada como um ordenamento fixo, dando-nos a impressão de que - com pouca ou nenhuma margem de objeção - a teoria é assim. Mas quando escolhemos defender que, tanto como arte quanto como teoria, nenhuma das noções da tonalidade harmônica é anistórica e puramente musical, passamos a lidar com algo que, entre o intra e o extra, é trânsito e transformação.

\section{Referências}

1. Abbagnano, Nicola. 1982. Dicionário de filosofia. São Paulo: Mestre Jou.

2. Barros, Guilherme Sauerbronn de, e Gerling Cristina Capparelli. 2009 Análise schenkeriana: interpretação e crítica. In: Budasz, Rogério (Org.). Pesquisa em música no Brasil: Métodos, domínios, perspectivas. Volume 1. p. 87-121. Goiânia: ANPPOM.

3. Beard, David e Gloag, Kenneth. 2006. Musicology: the key concepts. London: Routledge.

4. Bernard, Jonathan W. 1980. The principle and the elements: Rameau's "controversy with d'Alembert". Journal of Music Theory, v. 24, n, 1, p. 37-62.

5. Bernstein, David W. 2006. Nineteenth-century harmonic theory: The AustroGerman legacy. In: Christensen, Thomas (Ed.). The Cambridge history of Western music theory. Cambridge: Cambridge University Press, p. 778-811.

6. Bluteau, Raphael. 1713. Vocabulario Portuguez e Latino. Coimbra: Collegio das Artes da Companhia de Jesu. 
7. Boulez, Pierre. 1995. Apontamentos de aprendiz. São Paulo: Ed. Perspectiva.

8. Bukofzer, Manfred. 1947. Music in the baroque era. New York: Norton.

9. Candé, Roland de. 1989. A música, linguagem, estrutura e instrumentos. Lisboa: Edições 70.

10. Carvalho, Mario Vieira de. 2007. A tragédia da escuta: Luigi Nono e a música do século XX. Lisboa: Imprensa Nacional-Casa da Moeda.

11. Cassirer, Ernst. 1997. A filosofia do Iluminismo. Campinas: Ed. da Unicamp.

12. Christensen, Thomas. 1993. Rameau and musical thought in the enlightenment. Cambridge: Cambridge University Press.

13. _ 2001. Rameau, Jean-Philippe [\$5, bibliografia]. In: Sadie, Stanley (Ed.). The New Grove Dictionary of Music and Musicians. v. 20, p. 794-806. London: McMillan.

14. Dahlhaus, Carl. 1990. Studies in the origin of harmonic tonality. Oxford: Princeton University Press.

15. . 1999. La idea de la música absoluta. Barcelona: Idea Books.

16. Damschroder, David. 2008. Thinking about harmony: historical perspectives on analysis. Cambridge: Cambridge University Press.

17. Dobránszky, Enid Abreu. 1992. No tear de Palas: Imaginação e gênio no século XVII. Uma introdução. Campinas: Papirus; Ed. da Unicamp.

18. Fubini, Enrico. 1994. La estética musical desde la antigüedad hasta el siglo XX. Madrid: Alianza Musical.

19. 2002. Los enciclopedistas y la música. Valência: Ed. Universitat de Valência.

20. Gaines, James R. 2007. Uma noite no palácio da razão. Rio de Janeiro: Record.

21. Goethe, Johann Wolfgang von. 2005. Escritos sobre arte. São Paulo: Imprensa Oficial.

22. Grave, Floyd K., e Grave Margaret G. 1988. In praise of harmony: the teachings of Abbé Georg Joseph Vogler. Lincoln: University of Nebraska Press.

23. Hindemith, Paul. 1962. Practica de la composición a dos voces. Buenos Aires: Ricordi Americana.

24. Hyer, Brian. 2006. Tonality. In: Christensen, Thomas (Ed.). The Cambridge history of Western music theory. p. 726-751. Cambridge: Cambridge University Press.

25. Kerman, Joseph. 1987. Musicologia. São Paulo: Martins Fontes. 
MUSICA THEORICA Revista da Associação Brasileira de Teoria e Análise Musical 2018, v. 3, n. 2, p. 203-226 - Journal of the Brazilian Society for Music Theory and Analysis @ TeMA 2018 - ISSN 2525-5541

26. Koellreutter, Hans-Joachim. 1980. Harmonia funcional. São Paulo: Ricordi.

27. Kopp, David. 2002. Chromatic transformations in nineteenth-century music. Cambridge: Cambridge University Press.

28. Mann, Thomas. 2000. Doutor Fausto: a vida do compositor alemão Adrian Leverkühn narrada por um amigo. Rio de Janeiro: Nova Fronteira.

29. Mastropasqua, Mauro. 2011. Logica musicale: storia de un'idea. Bologna: Bonomia University Press.

30. Meyer, Leonard B. El estilo en la música. 2000. Teoria musical, história e ideologia. Madrid: Ed. Pirámide.

31. Montgomery, David L. 1992. The myth of organicism: from bad science to great art. The Musical Quarterly, v. 76, n. 1, p. 17-66.

32. Mora, José Ferrater. 2004. Dicionário de filosofia. São Paulo: Edições Loyola.

33. Moreno, Jairo. 2004. Musical representations, subjects, and objects: the construction of musical thought in Zarlino, Descartes, Rameau, and Weber. Bloomington: Indiana University Press.

34. Nattiez, Jean-Jacques. 1984. Harmonia. In: Enciclopédia Einaudi v. 3. Porto: Imprensa Nacional-Casa da Moeda, p. 245-271.

35. Oliveira, João Vicente Ganzarolli de. 2004. Descrição mínima de um renascimento pouco lembrado. Phoînix, Rio de Janeiro, v. 10, p. 144-166.

36. Osborne, Harold. 1983. Estética e teoria da arte. São Paulo: Cultrix.

37. Rameau, Jean-Philippe. 1750. Démonstration du principe de l'harmonie servant de base à tout l'art musical théorique et pratique. Paris: Ed. Durand e Fissot.

38. _. Treatise on harmony. New York: Dover Publications, 1971.

39. Rehding, Alexander. 2008. Hugo Riemann and the birth of modern musical thought. Cambridge: Cambridge University Press.

40. Rosen, Charles. 2004. Poetas românticos, críticos e outros loucos. Campinas: Ed. da Unicamp.

41. Ross, Alex. 2009. O resto é ruído. Escutando o século XX. São Paulo: Companhia das Letras.

42. Rousseau, Jean-Jacques. 2007. Diccionario de música. Madrid: Ediciones Akal.

43. . Ensaio sobre a origem das línguas. 2008. Campinas: Ed. da Unicamp. 
44. Santos, Boaventura de Sousa. 1988. Um discurso sobre as ciências na transição para uma ciência pós-moderna. Estudos Avançados, IEL / USP, v. 2, n. 2, p. 4671, maio/ago.

45. Saslaw, Janna K. e Walsh James P. 1996. Musical invariance as a cognitive structure: "multiple meaning" in the early nineteenth century. In: Bent, Ian (Ed.). Music theory in the age of romanticism. Cambridge: Cambridge University Press, p. 211-231.

46. Saslaw, Janna K. 1992. Gottfried Weber and the concept of Mehrdeutigkeit. Ph.D. dissertation. Columbia University.

47. Schenker, Heinrich. 1990. Tratado de armonia. Madrid: Real Musical.

48. Schoenberg, Arnold. 2004. Funções estruturais da harmonia. São Paulo: Via Lettera.

49. Schoenberg, Arnold. 2001. Harmonia. São Paulo: Ed. da Unesp.

50. Schuback, Márcia Sá Cavalcante. 1999. A doutrina dos sons de Goethe a caminho da música nova de Webern. Rio de Janeiro: Ed. URFJ.

51. Schwanitz, Dietrich. 2007. Cultura geral. São Paulo: Martins Fontes.

52. Scott, John. (Org.). 2010. Sociologia: conceitos-chave. Rio de Janeiro: Ed. Zahar.

53. Solie, Ruth A. 1980. The living work: organicism and musical analysis. 19thCentury Music, v. 4, n. 2, p. 147-156.

54. Tagg, Philip. 2005. Para qué sirve un musema? Antidepresivos y la gestión musical de la angustia. In: Ulhôa, Martha; Ochoa, Ana Maria (Org.). Música popular na América Latina: pontos de escuta. Porto Alegre: Ed. da UFRGS. p. 2251.

55. Tatarkiewicz, Władysław. 1989. Historia de la estética v. 2, La estética medieval. Madrid: Ediciones Akal.

56. __ 1991. Historia de la estética v. 3, La estética moderna (1400-1700). Madrid: Ediciones Akal.

57. 2002. Historia de seis ideas: arte, belleza, forma, creatividad, mímesis, experiencia estética. Madrid: Editorial Tecnos.

58. Videira, Mário. 2006. O romantismo e o belo musical. São Paulo: Ed. UNESP.

59. Wason, Robert W. 1995. Viennese harmonic theory from Albrechtsberger to Schenker and Schoenberg. Rochester, NY: University of Rochester Press.

60. Williams, Raymond. 1979. Marxismo e literatura. Rio de Janeiro: Zahar. 